\title{
DYNAMIC PRICING WITH UPDATED DEMAND FOR THE SPORTS AND ENTERTAINMENT TICKET INDUSTRY
}

\author{
${ }^{1}$ Naragain Phumchusri and ${ }^{2}$ Julie L. Swann \\ ${ }^{1}$ Department of Industrial Engineering, \\ Faculty of Engineering, Chulalongkorn University, Bangkok, Thailand \\ ${ }^{2}$ H.Milton Stewart School of Industrial and Systems Engineering, \\ Georgia Institute of Technology, Atlanta, Georgia, USA
}

Received 2014-03-06; Revised 2014-03-07; Accepted 2014-11-11

\begin{abstract}
Revenue Management (RM) helped increase profitability for many travel industries. Selling perishable products with a fixed event date, the Sports and Entertainment (S\&E) ticket industry can potentially benefit from RM ideas but has received less attention in the literature. In this study we develop dynamic pricing models for stochastic S\&E demand in a discrete finite time setting, where demand depends not only on ticket prices but also on remaining times until the show dates. We assume the show popularity is uncertain to the seller, but this information can be learned via Bayesian updates as early sales are revealed. We present stochastic dynamic programs for Sports and Entertainment tickets pricing decisions. We test the models using real data obtained from a major performance venue in the U.S. to understand properties of the model solutions and performance under different scenarios. Our results show that demand learning is most beneficial when the initial estimates are incorrect. In addition, we found it is less necessary for the seller to vary price every period if demand variation is low and/or a large amount of demand arrives close to the show dates. Overall, we found that the benefits from having flexibility of price changes and demand learning can complement each other to achieve as much as $8.15 \%$ revenue increase on average, as compared to static pricing.
\end{abstract}

Keywords: Dynamic Pricing, Demand Learning, Bayesian Updates, Sports and Entertainment Industry

\section{INTRODUCTION}

Revenue Management (RM) has attracted much attention and been proven as one of the most effective practices to increase profitability for many industries. RM first emerged in the airline industry in the context of passenger booking problems (Belobaba, 1987; Littlewood, 1972; Rothstein, 1971). Then, it has played important roles in improving the performance of many industries, selling fixed perishable capacity with high set-up costs such as hotels (Bitran and Gilbert, 1996; Bitran and Mondschein, 1995; Lieberman, 1992), cruise lines (Ladany and Arbel, 1991), passenger railways (Ciancimino et al., 1999) and rental car companies (Carol and Grimes, 1995; Geraghty and Johnson, 1997). Ultimately, RM is used to support decision making to achieve the goal of selling the right amount of product at the right price to the right customers at the right time (Bitran and Caldentey, 2003).

Dynamic pricing is an RM tool that is widely used to manage and control demand at different points of time. Sellers adjust prices to increase or decrease demand in the short run so that it can be matched with their available resources. The main objective of Corresponding Author: Naragain Phumchusri, Department of Industrial Engineering, Faculty of Engineering, Chulalongkorn University, Bangkok, Thailand 
dynamic pricing is to find an optimal dynamic policy to balance utilization of the available capacity so that the revenue can be maximized over the selling period. There are extensive papers exploring a variety of dynamic pricing topics (Biller et al., 2005; Chan et al., 2004; Gallego and van Ryzin, 1994; 1997; Kannan and Kopalle, 2001; Leloup and Deveaux, 2001; Levin et al., 2009; Maglaras and Meissner, 2006). While dynamic pricing has been intensively studied in the travel industries, the Sport and Entertainment (S\&E) industry is another business that has potential to be improved by the idea but still has not received as much attention (Drake et al., 2008).

There are approximately 1,953 sport stadiums and 236 performance venues in the United States, with the total revenue of 44.2 billion reported in 2009 (PricewaterhouseCoopers, 2010). Similar to the airline business, the number of the $\mathrm{S} \& \mathrm{E}$ tickets is fixed and they are "perishable" since they have no value after the event date. However, the S\&E industry's characteristics differ from airlines or hotels in many ways. First, a much higher percentage of entertainment tickets are purchased on the day of the show than on the day of a flight or on the day of a hotel stay (Drake et al., 2008). Secondly, while important factors of demand are date/time of a flight for airlines and day/month of a stay for hotels, the S\&E ticket demand is also very related to the sport teams or performance artists' popularity. Moreover, consumer tastes and economic conditions change over time and events vary from one year to another, so it is difficult to incorporate all uncertainties to precisely predict S\&E ticket sales. For these reasons, a different pricing model is necessary for the S\&E industry.

Although there are a number of studies that are related to ticket pricing (Courty, 2003; Deserpa, 1994; Rosen and Rosenfield, 1997) and the topic of price variation in the S\&E business (Leslie, 2004; Rascher, 1999), the previous research considered static pricing decisions where ticket prices remain constant for the entire selling horizon. It is generally because in the past, most event tickets were sold with a fixed price (independent of when the tickets were sold) due to the limited inventory tracking devices or ticket changes were done on an ad-hoc basis. However, in recent years, tools such as internet based selling systems have become widely available, providing information for real-time demand observations. From our discussions with a performing arts consulting firm, there has been a significant interest from a number of performance arts organizations for methods to apply dynamic discounts/premiums pricing to more effectively manage demand and increase revenue.
For new products (without past sales information) and/or products whose demand patterns may deviate significantly from past history, demand characterization is difficult (Lan et al., 2008). Likewise, the S\&E demand can be uncertain, especially for a new show or a sports team with varying performance. So, the seller cannot totally rely on past sales history when predicting demand. Early sales observations can be useful for demand information updates. For example, after the selling time starts, the ticket sellers will have a clearer picture whether the games (or shows) are likely to have high or low sales. In this study, we consider stochastic S\&E ticket demand and incorporate demand learning with Bayesian updates. A stochastic setting is appropriate to capture real-life situations when the paths of demand over time is difficult to be accurately predicted (Bitran and Caldentey, 2003); while demand learning allows the seller to update his beliefs as uncertainty reveals itself.

In this study, we assume ticket demand in each period follows a Poisson distribution, where its rate is affected by three components; (1) the artists/sport teams' popularity, (2) the ticket price and (3) the remaining time until the show date. Including timing effects for the S\&E ticket demand is motivated by the actual data. Figure 1 depicts the average number of tickets sold for 108 shows performed in a major performance venue in the U.S. during the 2007-2008 season, where the horizontal axis represents the number of months prior to the show dates. The upper and lower lines represent the average plus and minus one standard deviation, respectively. We can see in Fig. 1 that the average number of seats sold each month is dependent on time prior to the show and it generally increases when the time is closer to the event date.

In our demand model, the seller can characterize price effects and timing effects on demand, but he has incomplete information about the event popularity (i.e., the base demand rate). The seller forecasts the base demand rate's initial estimation and then uses the observed sales to update his belief about the upcoming period's demand. We develop dynamic pricing models in a discrete-finite-time selling horizon. In the first period, the seller determines the optimal base ticket price. In the following periods, the seller can offer discounts (decrease price) or charge premiums (increase price), with respect to the decided base price. We develop a dynamic pricing model in a discrete-finite-time selling horizon. In the first period, the seller determines the optimal base price. In the following periods, the seller can offer discounts (decrease price) or charge premiums (increase price), with respect to the decided base price. 
We develop a method for pricing and learning that allows us to address the following research questions:

- How can the observed sales be used in the demand learning process to improve the forecast and when is demand learning most beneficial?

- How are the optimal price changes related to model parameters such as price sensitivity and remaining inventory of unsold tickets?

This study is organized as follows. We begin by we discussing demand assumptions and describe how the observed sales are used to update the belief about the upcoming period's demand in the learning process. Section 3, we present the dynamic discounts/premiums pricing model, where the price discounts/premiums adjustment is allowed in every period and discuss the value of applying demand learning to the pricing model via the computational study. Finally, Section 4 concludes with a summary of insights from the results this study and discusses interesting future research ideas that this study could be extended further.

\section{DEMAND LEARNING MODEL}

In this section, we describe our demand model and show how the observed sales are used to update beliefs about demand in the upcoming periods.

In this model, the ticket demand in each period $\mathrm{t}$ is assumed to follow a Poisson process with rate $\Theta_{t}\left(p_{t}, \Gamma_{t}\right)$, which is affected by three components: (1) the ticket price, (2) the artists/sport teams' popularity and (3) the remaining time until the show date. Note that $\mathrm{p}_{\mathrm{t}}$ denotes the ticket price in period $t$ and $\Gamma_{t}$ denotes the base demand rate, which represents the expected popularity of the show. The overall demand rate is defined as follows:

$$
\Theta_{t}\left(p_{t}, \Gamma_{t}\right)=\phi\left(p_{t}\right) g(t) \Gamma_{t}
$$

where, $\phi\left(p_{t}\right)$ represents price effects (i.e., the probability of each arrival purchasing a ticket) and it is decreasing with price $p_{t}$. The demand timing effect, $g(t)$, is a decreasing function of $\mathrm{t}$ (where $t=n$ at beginning of the selling time and $t=0$ at the show/event time). This assumption is underlined from the data we observed (Fig. 1) that ticket demand tends to increase closer to the show date. Also, ticket demand is sensitive to price, which is intuitive.

From our discussions with the performing arts consulting firm, the show's popularity in customers' perspective is usually uncertain to the seller. It is usually difficult to correctly forecast demand. Therefore, in our model we assume there is incomplete information on the exact value of the base demand rate, $\Gamma_{t}$. At the beginning of the selling time $(t=n)$, we assume $\Gamma_{n}$ follows a Gamma distribution with a scale parameter of a and a shape parameter of $b$. In addition to the show's popularity, a and b may depend on the city in which the show is performed, since we may expect a higher base demand rate for the show taking place in a bigger city. A Gamma distribution allows the flexibility of the shape and position to be changed extensively via parameters a and $\mathrm{b}$, where empirically we found it a good match to past data. Let $M_{n}$ be the random demand in period $t=n$. The distribution of $M_{n}$, conditional on the base demand rate $\left(\Gamma_{n}=\gamma\right)$ and ticket price $\left(p_{n}\right)$, follows a Poisson distribution with rate $\phi\left(p_{n}\right) g(n) \gamma$. Thus, for demand in the first period, we have Equation 1:

$$
\begin{aligned}
& f\left(M_{n}=m \mid \Gamma_{n}=\gamma, p_{n}\right) \\
& =\frac{\left[\phi\left(p_{n}\right) g(n) \gamma\right]^{m} e^{-\phi\left(p_{n}\right) g(n) \gamma}}{m !}, \forall m \in\{0,1,2, \ldots\}
\end{aligned}
$$

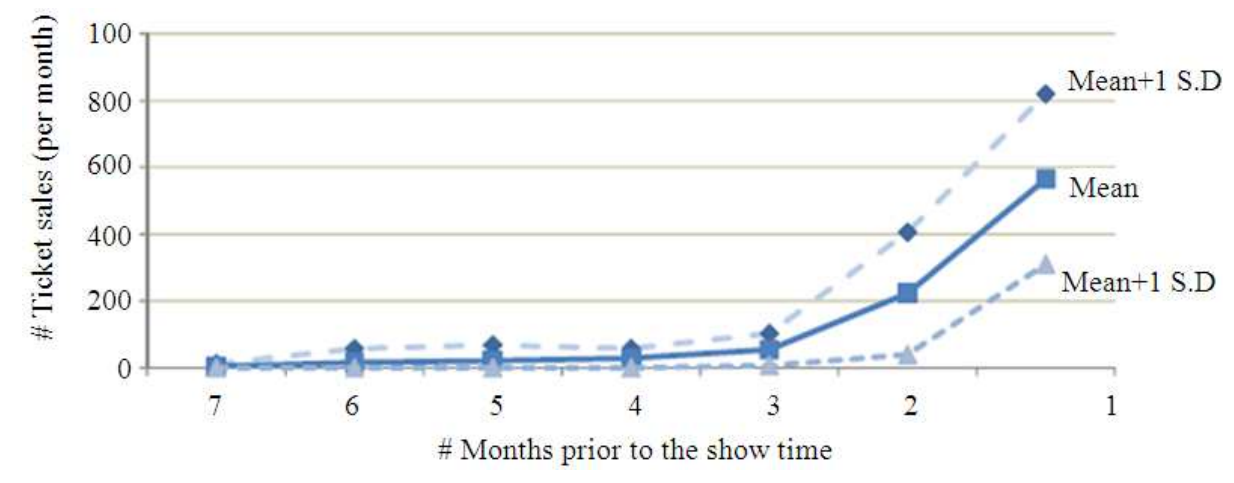

Fig. 1. The average ticket sales of 108 shows performed in a major performance venue in the U.S. during the 2007-2008 season, at different times prior to the show 
Similarly, the distribution of demand in period $t$ (denoted by), conditional on the base demand rate and ticket price, follows a Poisson distribution with rate, i.e., Equation 2:

$$
\begin{aligned}
& f\left(M_{t}=m \mid \Gamma_{t}=\gamma, p_{t}\right)=\frac{\left[\phi\left(p_{t}\right) g(t) \gamma\right]^{m} e^{-\phi\left(p_{t}\right) g(t) \gamma}}{m !}, \\
& \forall m \in\{0,1,2, \ldots\}, \forall t \in\{n-1, \ldots, 1\}
\end{aligned}
$$

Next, we identify the prior distribution of the demand in the first selling period $(t=n)$. From Bayes' rule, we have that the distribution of demand (when the price is $p_{n}$ ), unconditional on $\tau_{n}$, is given by Equation 3:

$$
\begin{aligned}
& f\left(M_{n}=m \mid p_{n}\right) \\
& =\int_{0}^{\infty} f\left(M_{n}=m \mid \Gamma_{n}=\gamma, p_{n}\right) f(\gamma) d \gamma \\
& =\int_{0}^{\infty}\left(\frac{\left[\phi\left(p_{n}\right) g(n) \gamma\right]^{m} e^{-\phi\left(p_{n}\right) g(n) \gamma}}{\mathrm{m} !}\right)\left(\frac{e^{-b y} \gamma^{\alpha-1} \mathrm{~b}^{\alpha}}{(\alpha-1) !}\right) d \gamma \\
& =\left(\begin{array}{c}
m+a-1 \\
m
\end{array}\right)\left(\frac{\phi\left(p_{n}\right) g(n)}{b+\phi\left(p_{n}\right) g(n)}\right)^{m}\left(\frac{b}{b+\phi\left(p_{n}\right) g(n)}\right)^{\alpha} \\
& \forall m \in\{0,1,2, \ldots\}
\end{aligned}
$$

where, $\left(M_{n}=m \mid \Gamma_{n}=\gamma, p_{n}\right)$ is given by (1) and $f(\gamma)$ is the distribution $\mathrm{f}$ function of $\Gamma_{n}$ (i.e., a Gamma distribution with parameters of a and b). From (3), we can see that $f\left(M_{n}=m\right)$ follows a Negative Binomial distribution with parameters of a and $\frac{b}{b+\phi\left(p_{n}\right) g(n)}$.

Denote $\mathrm{m}_{\mathrm{n}}$ as the actual sales in the first period $t=n$. After $m_{n}$ has been observed, the base demand rate in the next period, $\Gamma_{n-1}$, is updated. Using Bayes' rule, the posterior distribution of $\Gamma_{n-1}$ is as follows Equation 4:

$$
\begin{gathered}
f\left(\gamma \mid p_{n}, m_{n}\right)=\frac{f\left(M_{n}=m_{n} \mid p_{n}, \Gamma_{n-1}=\gamma\right) f(\gamma)}{\int_{0}^{\infty} f\left(M_{n}=m_{n} \mid p_{n}, \Gamma_{n-1}=\gamma\right) f(\gamma) d \gamma} \\
=\frac{e^{-\gamma\left(b+\phi\left(p_{n}\right) g(n)\right)} \gamma^{a+m_{n}-1}\left[b+\phi\left(p_{n}\right) g(n)\right]^{\alpha+m_{n}}}{\left(a+m_{n}-1\right) !}, \forall \gamma>0
\end{gathered}
$$

Thus, the posterior distribution of $\Gamma_{n-1}$ at the beginning of the next period $(t=n-1)$ follows a Gamma distribution with a scale parameter of $a+m_{n}$ and a shape parameter of $b+\phi\left(p_{n}\right) g(n)$.

From Bayes' rule, the distribution of demand in period $t=n-1$ is given by:

$$
\begin{aligned}
f\left(M_{n-1}=m \mid p_{n-1}, p_{n}, m_{n}\right) \\
\quad=\int_{0}^{\infty} f\left(M_{n-1}=m \mid \Gamma_{n-1}=\gamma, p_{n-1}\right) f\left(\gamma \mid p_{n}, m_{n}\right) d \gamma \\
\quad=\int_{0}^{\infty}\left(\frac{\left[\phi\left(p_{n-1}\right) \mathrm{g}(n-1) \gamma\right]^{m} \mathrm{e}^{-\phi\left(p_{n-1}\right) \mathrm{g}(n-1) \gamma}}{m !}\right) \\
\quad \times\left(\frac{e^{-\gamma\left[\mathrm{b}+\phi\left(p_{n}\right) \mathrm{g}(\mathrm{n})\right]} \gamma^{\mathrm{a}+m_{n}-1}\left[b+\phi\left(p_{n}\right) \mathrm{g}(n)\right]^{\mathrm{a}+m_{n}}}{\left(a+m_{n}-1\right) !}\right) d \gamma \\
\quad=\left(\begin{array}{c}
m+a+m_{n}-1 \\
m
\end{array}\right)\left(\frac{\phi\left(p_{n-1}\right) g(n-1)}{b+\phi\left(p_{n}\right) g(n)+\phi\left(p_{n-1}\right) g(n-1)}\right)^{m} \\
\quad \times\left(\frac{b+\phi\left(p_{n}\right) \mathrm{g}(n)}{b+\phi\left(p_{n}\right) g(n)+\phi\left(p_{n-1}\right) g(n-1)}\right)^{\alpha+\mathrm{m}_{n}}, \forall m \in\{0,1,2, \ldots\},
\end{aligned}
$$

where, $f\left(M_{n-1}=m \mid \Gamma_{n-1}=\gamma, p_{n-1}\right)$ is given by (2) for $t_{n-1}$ and $f\left(\gamma \mid m_{n}, p_{n}\right)$ is the distribution function of $\Gamma_{n-1}$, given by (4). We can see that $M_{n-1}$ follows a Negative Binomial distribution with parameters $\alpha+m_{n}$ and $\frac{b+\phi\left(p_{\mathrm{n}}\right) g(n)}{b+\phi\left(p_{n}\right) g(n)+\phi\left(p_{n-1}\right) g(n-1)}$. From the demand functions described above, we find that the base demand rate and the unconditional ticket demand distributions in any period $t$ can be summarized in the following Theorem.

\section{Theorem 1}

In period $\mathrm{t}$, where $n<t \leq 1$, we have:

- The base demand rate, $\Gamma_{t}$, follows a Gamma distribution with a scale parameter of $\alpha+\sum_{k=t+1}^{n} m_{k}$ and a shape parameter of $b+\sum_{k=t+1}^{n} \phi\left(p_{k}\right) g(k)$

- The unconditional ticket demand, Mt, follows a Negative Binomial distribution with parameters $a+\sum_{k=t+1}^{n} m_{k}$ and $\frac{b+\sum_{k=t+1}^{n} \phi\left(p_{k}\right) g(k)}{b+\sum_{k=t+1}^{n} \phi\left(p_{k}\right) g(k)+\phi\left(p_{t}\right) g(t)}$

Theorem 1 (i) and (ii) address the distribution of the base demand rate, $\Gamma_{t}$ and the unconditional demand, $M_{t}$, respectively. From Theorem 1 (ii), the distribution of demand in period $\mathrm{t}$ is given by:

$$
\begin{aligned}
f\left(M_{t}\right. & \left.=m \mid p_{t}, p_{t+1}, \ldots, p_{n}, m_{t+1}, \ldots, m_{n}\right) \\
& =\left(\begin{array}{c}
m+a+\sum_{k=t+1}^{n} m_{k}-1 \\
m
\end{array}\right)\left(\frac{\phi\left(p_{t}\right) g(t)}{A(t)}\right)^{m} \\
& \times\left(\frac{b+\sum_{k=t+1}^{n} \phi\left(p_{k}\right) g(k)}{A(t)}\right)^{a+} \sum_{k=t+1}^{n} n_{k}, \forall m \in\{0,1,2, \ldots\}
\end{aligned}
$$


where, $A(t)=b+\sum_{k=t+1}^{n} \phi\left(p_{k}\right) g(k)+\phi\left(p_{t}\right) g(t)$. Note that ticket demand takes non-negative integer values. The posterior Negative Binomial distribution of demand is advantageous since it provides the probability mass function for non-negative integers. Moreover, the shape and position can be changed extensively via its two parameters (Subrahmanyan and Shoemaker, 1996). From ticket sales data of the 2007-2008 season obtained from a performance venue in the U.S. (108 shows), Fig. 2 depicts the probability density plots of sales occurred at different times in the selling horizon; i.e., one, two, three and four months prior to the show time, respectively. Using the MaximumLikelihood method, the actual data was fitted to the Negative Binomial distribution, where the fitted values of mean and standard deviation were shown. From the Pearsons Chi-Square test (Plackett, 1983), we found that with a significant level of $5 \%$, the hypothesis that demand (from the venue's data) follows a Negative Binomial distribution was accepted for all graphs shown in Fig. 2.

Given the observed sales data, the seller updates his belief about demand in the next period. The following Proposition presents the relationships between the expected demand and key relevant factors.

\section{Theorem 2}

The expected demand in period $t$ is:

- Decreasing with the ticket price in period $t$

- Decreasing with selling prices offered in the past periods, $t+1, \ldots, n$

- Increasing with sales in the past periods, $t+1, \ldots, n$

From Observation 1, the expected demand in period $\mathrm{t}$ depends not only on $\mathrm{p}_{\mathrm{t}}$ but also on the history of prices charged, $P_{t+1}, \ldots P_{n}$. The result is intuitive because when the seller sold tickets at expensive prices in the past periods, it reduced past sales. This causes lower expected demand in the current period t since the observed sales are used to update belief about the upcoming demand. In other words, the lower (higher) the past sales, the lower (higher) the demand in the upcoming period is expected to be.

\section{DYNAMIC DISCOUNTS/PREMIUMS PRICING}

In this section we describe how the demand learning technique discussed in section 3 can be embedded in the ticket seller's dynamic pricing model. We begin with descriptions of key assumptions and present the "Dynamic discounts/premiums pricing" model, where price discounts/premiums adjustments are allowed in every period, in the context of a stochastic dynamic program in section 3.1. Computational analysis is then presented in section 3.2 to provide insights on the optimal pricing structures and the benefit of demand learning for the described pricing model.

\subsection{Model}

We consider a discrete finite time setting, where there are $n$ sub-periods from the beginning of the selling horizon to the event/show time. The time periods are numbered in reverse chronological order so that the beginning of the selling horizon is time $t=n$ and the show takes place at time $t=0$. At the beginning of the selling horizon $(t=n)$, there are $I_{n}$ number of tickets for sale. The number of tickets demanded and the actual sales in period $t$ are denoted by $d_{t}$ and $\mathrm{m}_{\mathrm{t}}$, respectively. If demand is less than inventory at the beginning of period, $I_{t}$, the ticket sales in period $t\left(m_{t}\right)$ are equal to $d_{t}$. However, if demand exceeds inventory $\left(d_{t}>I_{t}\right)$, the ticket sales $\mathrm{m}_{\mathrm{t}}$ will equal $I_{t}$.

In the first period of the selling horizon $(t=n)$, the seller determines the base price, $p_{n}$. Then, at time $t=n$ $1, \ldots, 1$, the seller observes past sales and decides whether to offer any discounts (reduce price) or charge premiums (increase price) and how much. Denote $\theta_{t}$ as the discount or premium for period $\mathrm{t}$ and we assume it is based on $p_{n}$, (i.e., customers pay $\theta_{t} p_{n}$ for each ticket in period $t$ ). If $\theta_{t}<1$, then $\theta_{t}$ is considered as a price discount; otherwise, it is a price premium. Define at as the ticket seller's action (or decision) at time $t$; we have:

$$
\alpha_{\mathrm{t}}= \begin{cases}p_{n} & \text { if } t=n \\ \theta_{t} & \text { if } t=n-1, \ldots, 1\end{cases}
$$

Let $V_{t} h_{t}$ denote the maximum expected revenue obtained from time period $t$ until the time of the show/event (at $t=0$ ), given the history at the beginning of period $t$ is $h_{t}=\left(h_{t+1}, \alpha_{t+1}, m_{t+1}, I_{t}\right)$. Note that $\mathrm{h}_{\mathrm{t}}$ consists of the history of the previous period $t+1$ (i.e., the action and the number of ticket sold in the previous period $t+1$ ), as well as the current inventory level $\left(I_{t}\right)$. At the beginning of the selling horizon $(t=n)$, we have $h_{n}=I_{n}$ since there is no prior information. We assume the seller is risk neutral, so the backwards recursion of the revenue maximization problem can be written as Equation 5:

$$
\begin{gathered}
V_{t}\left(h_{t}\right)=\max _{\alpha_{\mathrm{t}} \in \mathrm{A}_{\mathrm{t}}} E\left[R_{t}\left(\alpha_{t}\right)+V_{t-1} h_{t-1} \mid m_{n}, \ldots, m_{t+1}\right. \\
\left.\phi\left(p_{n}\right), \ldots, \phi\left(p_{n+1}\right) ; g(n), \ldots, g(t+1)\right]
\end{gathered}
$$

where, $R_{t}\left(a_{t}\right)$ is defined as the immediate revenue received in period t when the seller's action is at; i.e.,: 


$$
R_{t}\left(\alpha_{t}\right)=\left\{\begin{array}{l}
\alpha_{\mathrm{n}} \min \left\{I_{n}, d_{n}\left(\alpha_{n}\right)\right\}=p_{n} \min \left\{I_{n}, d_{n}\left(p_{n}\right)\right\} \\
\text { if } \mathrm{t}=\mathrm{n} ; \\
\alpha_{t} p_{n} \min \left\{I_{t}, d_{t}\left(\alpha_{t}\right)\right\}=\theta_{t} p_{n} \min \left\{I_{t}, d_{t}\left(\theta_{t} p_{n}\right)\right\} \\
\text { if } t=n-1, \ldots, 1,
\end{array}\right.
$$

where, $i_{t}=\max \left\{0, \quad l_{t+1}-d_{t+1}\left(\alpha_{t+1}\right)\right\}$ The boundary conditions are as follow Equation 6 and 7:

$$
\begin{aligned}
& V_{0}\left(h_{0}\right)=0, \forall h_{0} \\
& V_{t}\left(h_{t}=\left(h_{t+1}, a_{t+1}, m_{t+1}, 0\right)\right)=0, " t
\end{aligned}
$$

Condition (6) means there is zero salvage value of any unsold tickets at the event time $(t=0)$. Condition (7) states that when all tickets have already been sold, the revenue from any period t on is zero since there are no tickets left for sale. The stochastic dynamic program can be solved by backwards induction starting at the final period, $t=1$, to period $t=n$. The following example is a special case where the selling time is divided into two periods, $n=2$.

\subsection{Computational Experiments}

In this section, we perform computational experiments for the dynamic discounts/premiums pricing model, with the goal of understanding the properties of the optimal solutions and the model performance under different situations. Specifically, we consider: (1) How the remaining inventory affects the expected base demand rate and the optimal discounts/premiums pricing policy and (2) how the performance of the dynamic discounts/premiums pricing model with demand learning is compared to the model without demand learning and when demand learning is most beneficial.

\subsection{Effects of the Remaining Inventory of Unsold Tickets}

In each period, the seller can observe how many unsold tickets remained in inventory. This section explores how the seller's expectation and optimal decisions are affected by the inventory information. Let us consider the following example. A ticket seller has 300 tickets for sale in a selling season with $n=2$. Let the probability of each arrival purchasing a ticket (the price effect function) be $\phi\left(p_{t}\right)=e^{-w p_{t}}$, where $\mathrm{w}$ is a known nonnegative scalar. Note that with this form of price effect, the demand rate equals $g(t) \Gamma_{t}$ when $p_{t}$ equals 0 and the rate approaches 0 as $p t$ is very large. This form of exponential price effect function has been generally used in the marketing literature since it was found to very well fit with the empirical data (Aviv and Pazgal, 2002).
Let the timing effect be $g(2)=1$ and $g(1)=u$, (where $u>1$ since we assume higher demand in the period closer to the show date). At the beginning of the selling horizon $(t=2)$, the seller believes that ticket demand is Poisson, with the base rate $\left(\Gamma_{2}\right)$ following a Gamma distribution with parameters $a=4$ and $b=0.04$ (This choice of a and $\mathrm{b}$ follows from an example of actual ticket demand data we observed). In this period $(t=2)$, the seller determines the optimal base ticket price, $p_{2}{ }_{2}$, from a discrete set $P_{2}=\{30$, $35, \ldots, 75,80\}$. After he observes how many tickets have been sold, the seller updates his belief with demand learning techniques presented in section 3 and determines the optimal price discount/premium, $\theta_{1}^{*}$, to charge in period $t=$ 1 from a discrete set $\theta_{1}=\{70 \%, 75 \%, \ldots, 115 \%, 120 \%\}$.

Figure 3 presents the updated mean demand for period $t=1$ at different values of remaining inventory from the past period (where the price sensitivity parameters $(w)$ equal $0.018, \quad 0.020$ and 0.022 , respectively (Parameter values for the price sensitivity parameters (w) in this experiment result in shifts of $0.9 \%-1.1 \%$ (at $\mathrm{p} 1=50$ ) which is consistent with data we have seen). As expected, at the same values of remaining inventory, the graph for $\mathrm{w}=0.018$ is the highest and the graph for $w=0.022$ is the lowest in Fig. 3, since a higher price sensitivity leads to lower expected demand. Moreover, considering the trends, we can see that the higher number of tickets left in inventory (i.e., the lower number of tickets already sold), the lower mean demand the seller expects for the next period. This is consistent with analytical results in Theorem 2 (iii) in Section 3 that the expected mean demand is increasing with observed sales in the past periods (so it is decreasing with the leftover inventory). The finding is rational because having a large number of tickets sold in the past periods (or a few number of tickets left in the inventory) can be an indicator of show popularity and it is likely that high demand will occur in the next period as well.

We solve the described problem by the stochastic dynamic program described in section 4.1. The optimal base price at the beginning of the selling horizon $(t=2)$ is 95. After sales are realized, the seller's optimal discount/premium pricing for period $t=1$ is shown in Fig. 4, where the horizontal axis represents different values of leftover inventory, $I_{1}$. Note that different lines in Fig. 4a represent different price sensitivity parameters, i.e., $w$ equals $0.018,0.020$ and 0.022 , respectively; while different lines in Fig. $4 \mathbf{b}$ represent different timing effect parameters, i.e., u equals 1.7, $2.0,2.3$, respectively. 
Naragain Phumchusri and Julie L. Swann / Journal of Computer Science 10 (11): 2240-2252, 2014
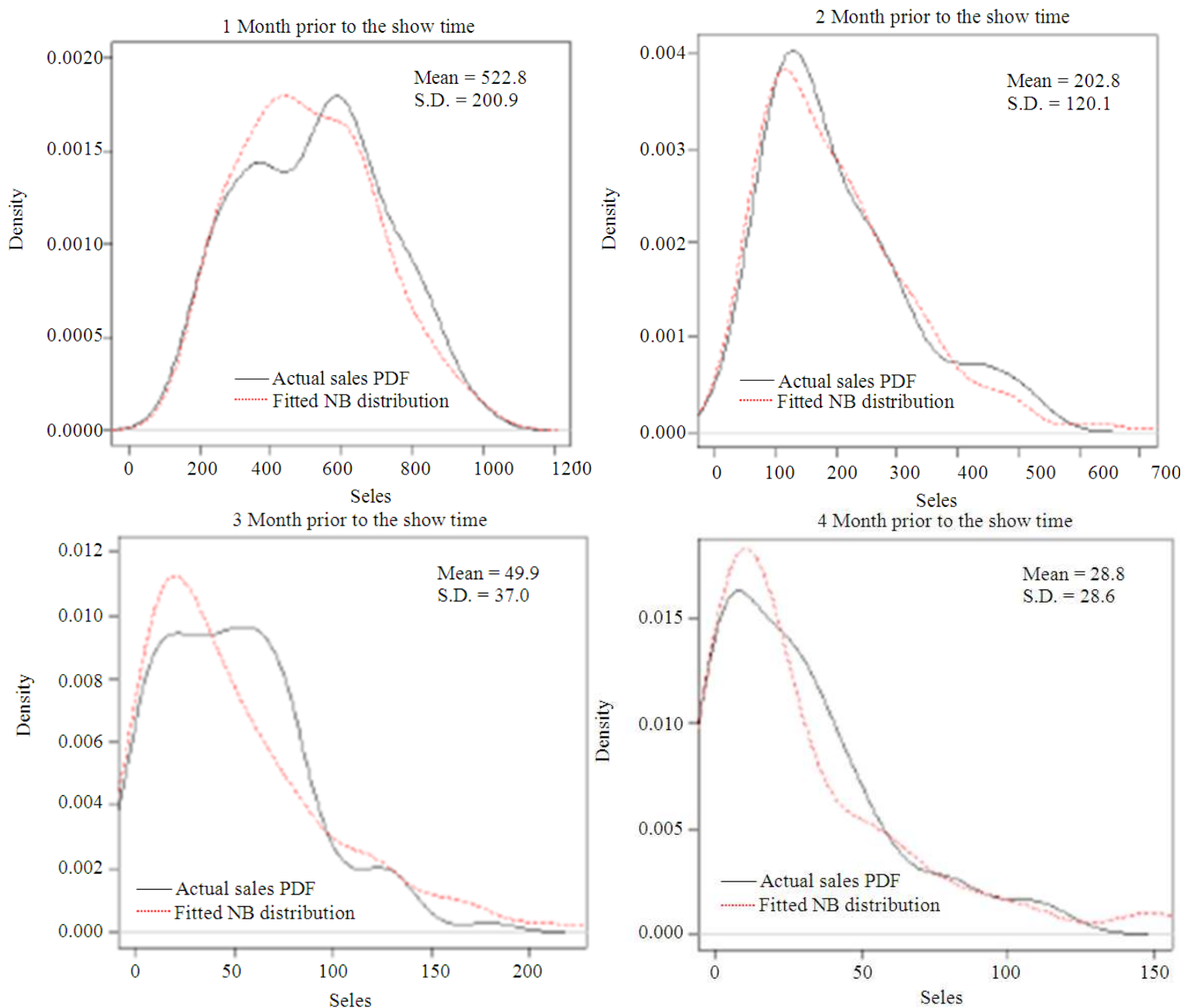

Fig. 2. The probability density plots of ticket sales from a major performance venue in the U.S. (during the 2007-2008 season)

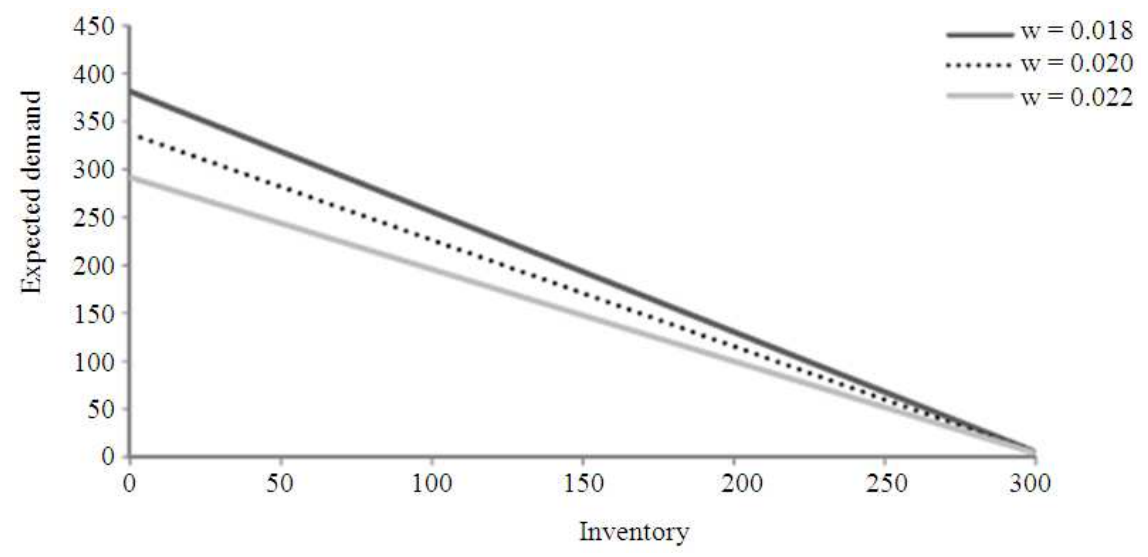

Fig. 3. The expected demand for the last period $(t=1)$ at different values of remaining inventory 
Optimal price promotions/premiums in the last period $(\mathrm{t}=1)$

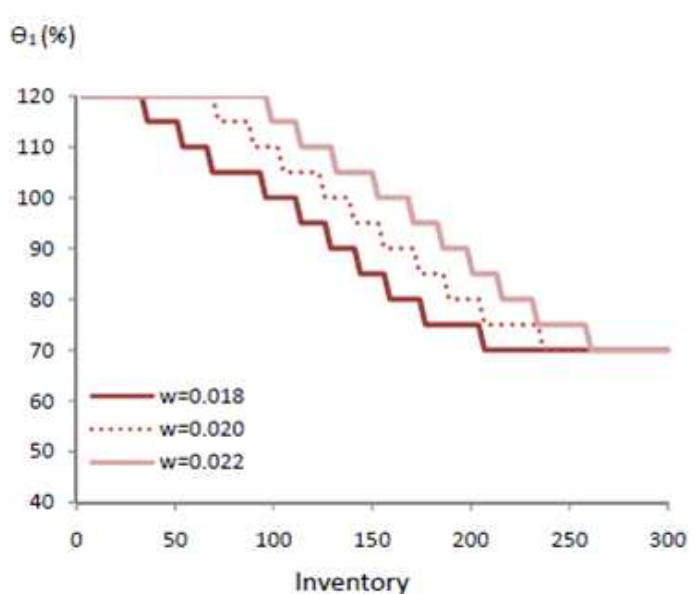

(a)

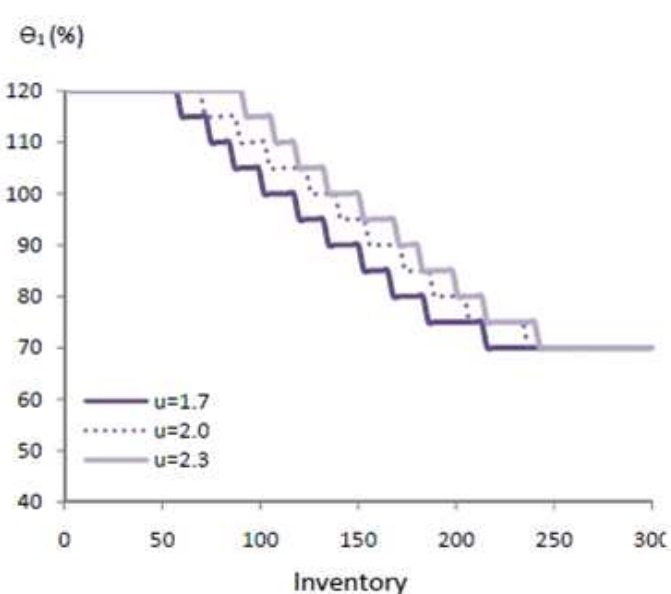

(b)

Fig. 4. The optimal discounts/premiums pricing for the last period $(t=1)$ at different values of leftover inventory, where $(\mathrm{a}) \mathrm{w}=$ $0.018,0.020,0.022$ (b) $\mathrm{u}=1.7,2.0$ and 2.3 , (a) at different price sensitivities (where $\mathrm{u}=2$ ) (b) at different timing effects $($ where $\mathrm{w}=0.020)$

\section{Observation 1}

The optimal ticket price discount/ premium, $\theta_{\mathrm{t}}$, is nonincreasing with the amount of leftover inventory observed at the beginning of the period.

Similar to other sets of experiment results we have explored, Observation 1 states that the higher the inventory, the lower the percentage of the base price that should be charged in the last period $(t=1)$. This result is consistent with other studies of dynamic pricing with no demand learning where the optimal price is found to be non-increasing with the remaining inventory (Chatwin, 2000; Feng and Xiao, 1999; Zhao and Zheng, 2000). In addition, we can see in Fig. 4a that at the same level of inventory, the higher the price sensitivity, the lower the optimal $\theta_{1}$. The timing effect parameter (u) also impacts the optimal $\theta_{1}$. From Fig. $\mathbf{4 b}$, at the same inventory level, the line with $u=2.3$ is the highest and the line with $\mathrm{u}=$ 1.7 is the lowest It implies when high demand is expected in the last period, it is less necessary for the seller to offer a deep discount (since there is a lower risk of having empty seats).

Next, we examine benefits of demand learning and identify which situations are most worthwhile for applying the learning process.

\subsection{Benefits of Demand Learning Process}

In this section, we study how the performance of the dynamic discount/premium pricing model with demand learning compares to the model without demand learning. The insights will allow us to identify which situations are most worthwhile to apply the learning process. The Demand Learning (DL) model incorporates observed sales in updating the belief of the next period's demand, while the No Demand Learning (NoDL) model does not. Thus, when the seller applies the NoDL model, in every period he uses the same estimated base demand rate as in the first period. We capture the DL and the NoDL model performances by comparing revenues obtained from each model to the revenue under perfect information. Note that under perfect information, the seller knows the true base demand without uncertainty and he optimizes his prices based on the true value. Define $\mathrm{PFM}_{\mathrm{DL}}$ as the performance of demand learning, i.e., $\quad P F M_{D L}=\frac{\text { Revenue of demand learning mod el }}{\text { Revenue of perfect } \inf \text { ormationcase }} \times 100$ and $\mathrm{PFM}_{\mathrm{NoDL}}$ as the performance of the no demand learning model, i.e., $P F M_{\text {NoDL }}=\frac{\text { Revenue of demand learning } \bmod \text { el }}{\text { Revenue of perfect } \text { inf } \text { ormationcase }} \times 100$

The closer $\mathrm{PFM}_{\mathrm{DL}}$ and $\mathrm{PFM}_{\mathrm{NoDL}}$ are to 100 , the better their performances are as compared to the perfect information case, although the latter may not be achievable.

Consider a ticket seller having 100 tickets for sale in a two-period selling horizon, where the timing effects are $g(2)=1$ and $g(1)=u, u>1$. The price effect function is $\phi\left(p_{t}\right)=e^{-0.02 p t}$. At the beginning of the selling time $(t=$ $2)$, the seller determines the optimal base ticket price, $p_{2}^{*}$, 
from a discrete set $P_{2}=\{50,55, \ldots, 95,100\}$. Then in the next period $(t=1)$, he determines the optimal price discount/premium $\left(\theta_{1}^{*}\right)$ from a discrete set $\Theta_{1}=\{70 \%$, $75, \ldots, 115,120 \%\}$.

Let us consider what happens if the ticket seller misestimates demand. For instance, suppose the true base demand rate in the first period $(t=2)$ is $\gamma$, while the seller believes the base demand rate follows Gamma distribution with parameters a and $b$, respectively. Note that the expected value of the base demand rate in this case equals $\frac{\alpha}{b}$ and the variance equals $\frac{\alpha}{b_{2}}$ (for Gamma distribution). Thus, the demand is overestimated if the seller believes that $\frac{\alpha}{b}$ is greater than the true base demand rate, $\gamma$ and the demand is underestimated otherwise.

In the following example, let the true base demand rate, $\gamma$, be 120 . Fig. 5 shows the chosen prices for the first and the second periods when the seller's estimates of the mean base demand rate $\left(\frac{\alpha}{b}\right)$ are $30,60, \ldots, 210$, 240 , respectively. The second period $(t=1)$ price equals the first period $(t=2)$ price times the discount/premium of the second period $\left(p_{1}=p_{2} \times \theta_{1}\right)$. In case $1, u=2.0$ and the optimal prices under perfect information are 75 and 56 for the first and the second period (in case 2 with $\mathrm{u}=$ 2.3 , they are 80 and 60 , respectively). We can see from Fig. 6 that in the first period, both DL and NoDL models choose similar prices for almost all values of $\frac{\alpha}{b}$. However, when the base demand rate is underestimated, i.e., $\frac{\alpha}{b}<120$, the DL model's prices for the second period are higher than the NoDL model's. Due to the ability of updating demand, the DL model uses the observed sales to adjust the true base demand rate's distribution for the next period. With the DL model, the seller realizes in the second period that he has underestimated the rate and then decides to charge higher prices than he would have done without Demand Learning (NoDL). Similar reason applies when the base demand rate is overestimated, where the second period's prices chosen by the DL model are lower than the NoDL model.

Considering the performance of each model, Fig. 6. shows $\mathrm{PFM}_{\mathrm{DL}}$ and $\mathrm{PFM}_{\mathrm{NoDL}}$, where the horizontal axis represents different estimates of $\frac{\alpha}{b}$ and the true value is indicated.

\section{Observation 2}

We found that:

- Demand Learning (DL) is most beneficial, as compared to No Demand Learning (NoDL) when the initial estimation is inaccurate (with up to 8$11 \%$ improvement in revenue when the misestimates are high)

- The marginal benefit of the DL model over the NoDL model is higher when a greater amount of demand arrives in the last period (approximately $5.4 \%$ improvement in revenue on average for case 2 , as compare to $3.9 \%$ for case 1 )

- The underestimation of the base demand rate when using the DL model causes fewer revenue loss as compared to overestimation

As we can see in Fig. 6, when the misestimates of the base demand rate are fairly large, $P F M_{D L}$ is greater than $P F M_{N o D L}$ for both graphs. It implies demand learning can help increase revenue, compared to no learning. The intuition is that when there are estimation errors, observed sales are effectively used since the inaccurate estimation can be corrected for an updated belief of demand in the next period. For example, if there is high uncertainty about the show's popularity (e.g., a new show with no records of past sales), it can be difficult for the ticket seller to identify a correct value of the show's base demand rate. The seller can start with a rough estimate of the base demand rate and then use the observed sales to update his belief.

In addition to the demand pace, we observe that demand learning affects the performance difference between the two models. Specifically, the dynamic timing model's performance is closer to the dynamic discounts/premiums pricing model's when demand learning is not allowed (as $P F M_{D T}$ is closer to 100 in this case). It indicates limiting the frequency of price changes is less disadvantageous, compared to allowing price changes every period, when the seller does not use observed sales to update his belief of demand. An explanation is when the seller allows demand learning, new information is received every period. So, it can be more beneficial to change price often, according to the updated demand. Adjusting price regularly as in the dynamic discounts/premiums pricing model can lead to higher revenue, especially with an integration of demand learning implementation. This observation is consistent with results across the set of computational experiments we performed, using different demand parameters. 
Naragain Phumchusri and Julie L. Swann / Journal of Computer Science 10 (11): 2240-2252, 2014

Price for the first and the second periods when using the DL and NoDL models
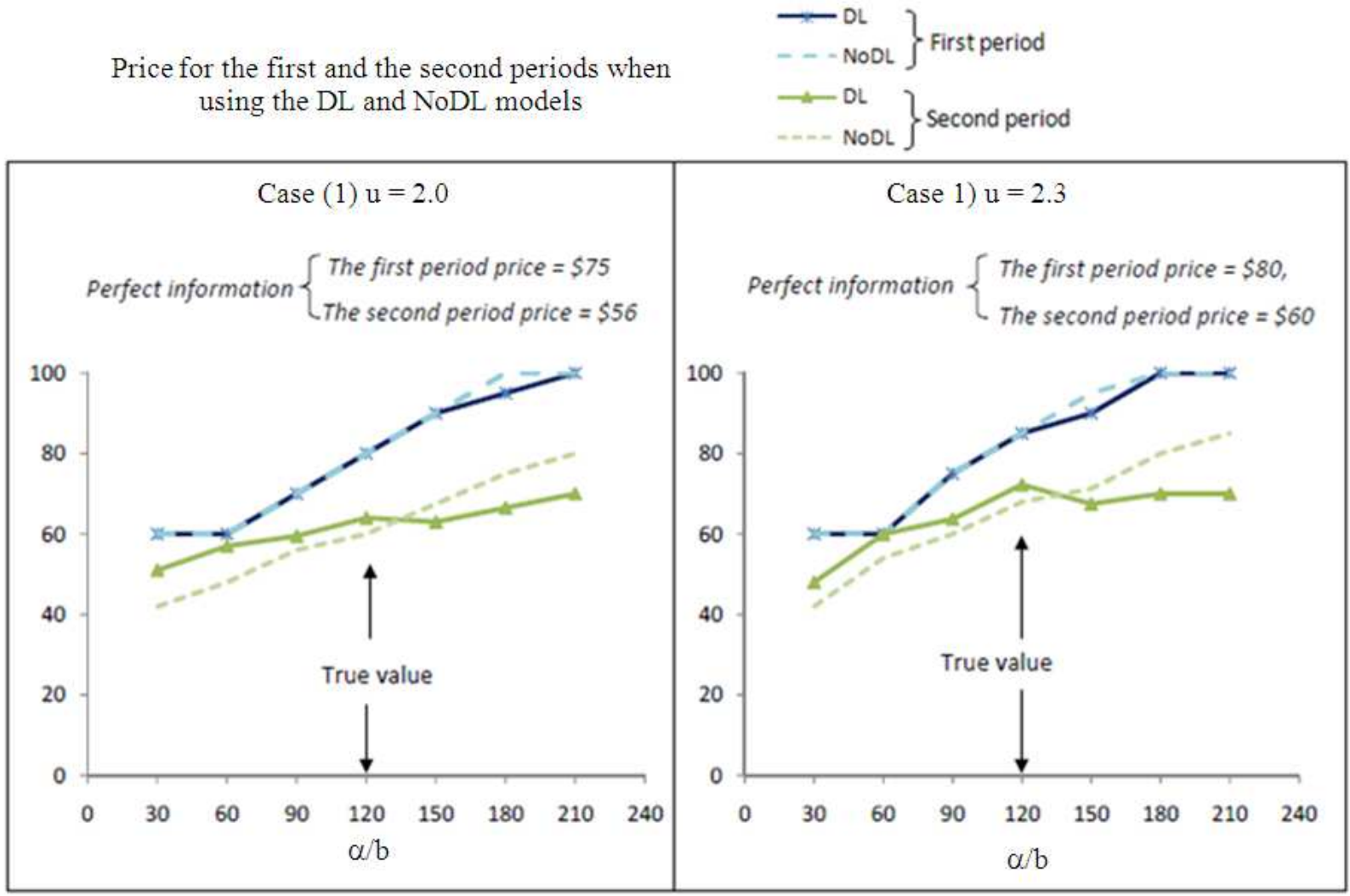

Fig. 5. The optimal prices for the first and the second periods when using the DL and the NoDL models

$\mathrm{PFM}_{\mathrm{DL}}$ and $\mathrm{PFM}_{\mathrm{NoDL}}$ at different estimates of $\alpha \mathrm{b}$
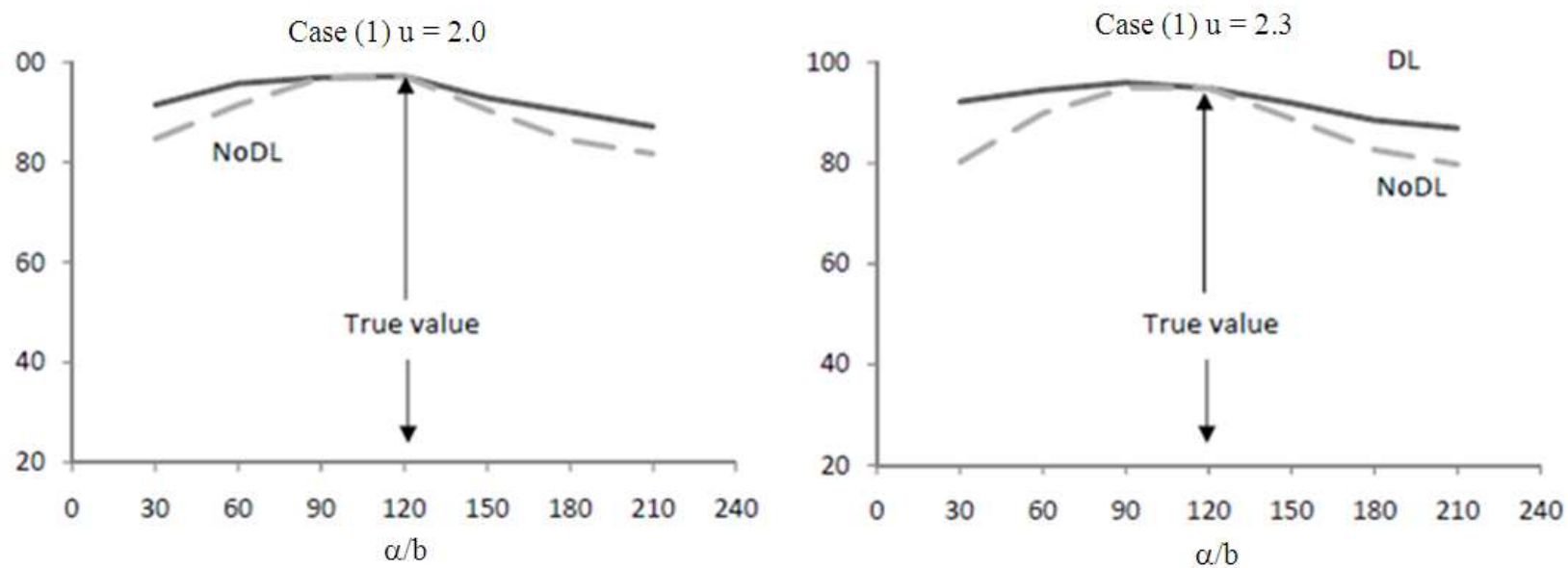

Fig. 6. Performances of the DL and the NoDL models at different estimates of $\frac{\alpha}{b}$, when the timing effects, u, are 2.0 (the left diagram) or 2.3 (the right diagram) 


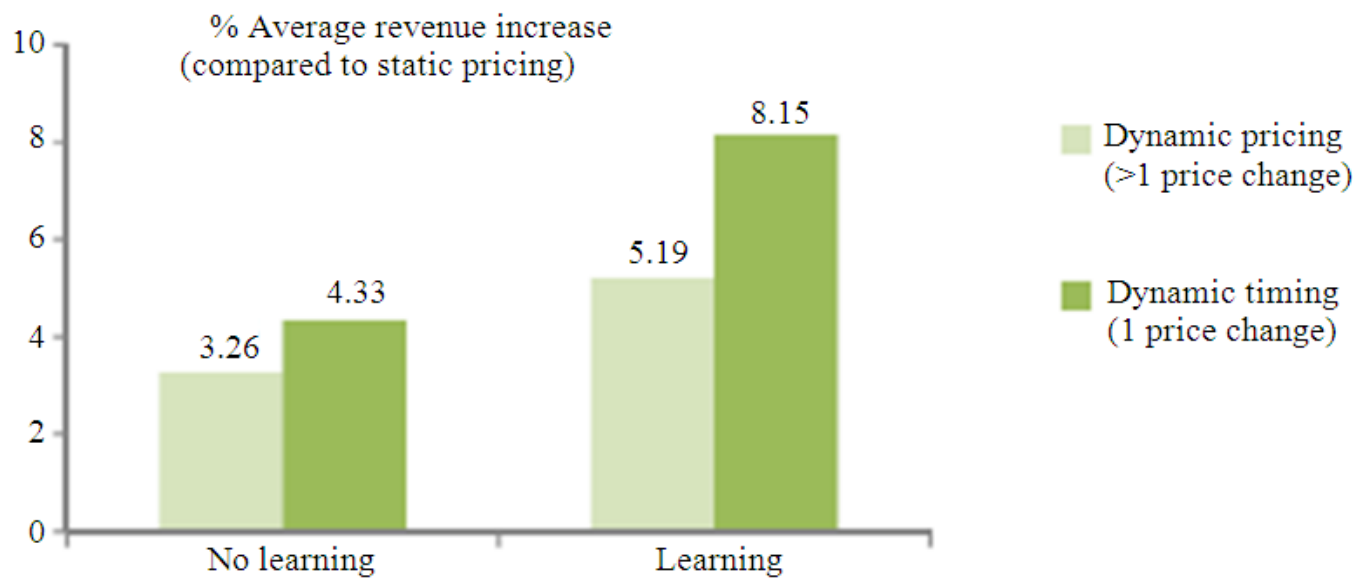

Fig. 7. The average percentage revenue increase(from static pricing policy) under different scenarios

We conclude this section by exploring the benefit gained from dynamic pricing as compared to static pricing. Figure 7 shows the average percentage revenue increase from implementing the dynamic discounts/ premiums pricing model and the dynamic timing model, with demand leaning and without demand learning, respectively. We observe that dynamic pricing (without demand learning) can help increase revenue by approximately $3.26-4.33 \%$, compared to static pricing. When demand learning is incorporated with one price change (dynamic timing model), the average revenue increase is approximately $5.19 \%$. Moreover, we found that the benefits from having flexibility of price changes (dynamic discounts/premiums pricing model) and demand learning can complement each other to achieve as much as $8.15 \%$ revenue increase.

\section{CONCLUSION}

While Revenue Management (RM) has been intensively studied in the travel industries, Sport and Entertainment (S\&E) also has a great potential to be improved by this idea but still has not obtained much attention in the literature. In addition, there may be models or insights from the S\&E industry that may apply to other RM contexts. In this study, we developed pricing and timing models for stochastic S\&E ticket demand in the existence of demand learning with Bayesian updates to reduce uncertainty and improve forecast. We also allow flexibility of demand being affected by time since in the S\&E industry, we observed significantly higher sales when it is closer to the end of the selling horizon.
We found that the optimal price discount/premium for the upcoming period is non-increasing with the amount of remaining inventory observed at the beginning of the period. To identify the benefit of demand learning, we compared the described model to a similar model without learning. We observed that demand learning is most beneficial when the initial demand estimation is inaccurate since the seller can correct his belief after observing the actual sales (with up to 8-11\% improvement in revenue when the misestimation is high). In addition, our results showed: When incorporating demand learning, the underestimation of the base demand rate causes less revenue loss as compared to overestimation. This implies a risk-averse seller who tends to underestimate the demand rate may obtain higher revenue than a risk-taker seller who overestimates it.

It is worthwhile to note that our model is suitable for situations when ticket demand is sensitive to both price and time of the selling season, according to our demand learning model assumption. A challenging task is to identify this function correctly to help this model compute the suitable ticket price for each selling period. There are several possible extensions of this study. First, our model assumes demand uncertainty comes from the base demand rate, while the price and the timing effects are unchanging. One could extend the model to allow imperfect information on price and/or timing sensitivities to explore the form of the resulting posterior distribution. We expect the distribution will be more complex in those cases, but it could be interesting to examine if the benefit can offset the higher complexity. A second promising extension is a pricing model with demand learning for substitutable products, e.g., substitutable seating sections 
or shows. If the ticket seller would like to allow different discounts/premiums for different types of seats or different days of the same performance, it can be useful to study how he can employ the observed sales to predict future demand for a variety of substitutable products (although there may not exist a closed form posterior distribution for each of them). Another possible extension is a dynamic pricing model that allows price adjustment only once. Each period, the seller needs to decide whether or not he should reduce or increase price and he has only one chance to do so. This model can be applied to situations when adjusting price frequently is costly or not preferable.

Since dynamic pricing is fairly new for the $\mathrm{S} \& \mathrm{E}$ business, an empirical work exploring the short-term and long-term effects of this revenue management idea could be useful. Obviously, there is still room for revenue management improvement for the Sports and Entertainment ticket industry and we hope our study will encourage future research in this area.

\section{REFERENCES}

Aviv, Y. and A. Pazgal, 2002. Pricing of short life-cycle products through active learning. Working paper. Washington University in St. Louis.

Belobaba, P., 1987. Airline yield management: An overview of seat inventory control. Trans. Sci., 21: 63-73.

Biller, S., L. Chan, D. Simchi-Levi and J. Swann, 2005. Dynamic pricing and the directto-customer model in the automotive industry. Elec. Commerce Res., 5: 309-334. DOI: 10.1007/s10660-005-6161-4

Bitran, G. and S. Gilbert, 1996. Managing hotel reservations with uncertain arrivals. Operat. Res., 44: 15-49.

Bitran, G. and S. Mondschein, 1995. An application of yield management to the hotel industry considering multiple stays. Operat. Res., 43: 427-443.

Bitran, R. and R. Caldentey, 2003. Pricing models for revenue management. Manufactur. Service Operat. Manage., 5: 203-229.

Carol, W. and R. Grimes, 1995. Evolutionary change in product management: Experiences in the car rental industry. Interfaces, 25: 84-104.

Chan, L., Z. Shen, D. Simchi-Levi and J. Swann, 2004. Coordination of Pricing and Inventory Decisions: A Survey and Classification. In: Handbook of Quantitative Supply Chain Analysis: Modeling in the E-Business Era, Simchi-Levi, D. (Ed.), Kluwer Academic, ISBN-10: 1402079524, pp: 335-392.
Chatwin, R., 2000. Optimal dynamic pricing of perishable products with stochastic demand and a finite set of prices. Eur. J. Operat. Res., 125: 149174. DOI: $10.1016 / \mathrm{S} 0377-2217(99) 00211-8$

Ciancimino, A., G. Inzerillo, S. Lucidi and L. Palagi, 1999. A mathematical programming approach for the solution of the railway yield management problem. Trans. Sci., 33: 168-181. DOI: 10.1287/trsc.33.2.168

Courty, P., 2003. Ticket pricing under demand uncertainty. J. Law Econ., 46: 627-652. DOI: $10.1086 / 377117$

Deserpa, A., 1994. To err is rational: A theory of excess demand for tickets. Managerial Decis. Econ., 15: 511-518. DOI: 10.1002/mde.4090150513

Drake, M.J., S. Duran, P. Griffin and J. Swann, 2008. Optimal timing of switches between product sales for sports and entertainment tickets. Naval Res. Logist., 55: 59-75. DOI: 10.1002/nav.20266

Feng, Y. and B. Xiao, 1999. Maximizing revenues of perishable assets with a risk factor. Operat. Res., 47: 337-341. DOI: 10.1287/opre.47.2.337

Gallego, G. and G. van Ryzin, 1994. Optimal dynamic pricing of inventories with stochastic demand over finite horizons. Manage. Sci., 40: 999-1020. DOI: 10.1287/mnsc. 40.8 .999

Gallego, G. and G. van Ryzin, 1997. A multiproduct dynamic pricing problem and its applications to network yield management. Operat. Res., 45: 2441. DOI: $10.1287 /$ opre.45.1.24

Geraghty, M.K. and E. Johnson, 1997. Revenue management saves national car rental. Interfaces, 27: 107-127.

Kannan, P. and P. Kopalle, 2001. Dynamic pricing on the internet: Importance and implications for consumer behavior. Int. J. Elec. Commerce, 5: 63-83.

Ladany, S. and A. Arbel, 1991. Optimal cruise-liner passenger cabin pricing policy. Eur. J. Operat. Res., 55: 136-147. DOI: 10.1016/0377-2217(91)90219-L

Lan, Y., H. Gao, M. Ball and I. Karaesmen, 2008. Revenue management with limited demand information. Manage. Sci., 54: 1594-1609. DOI: 10.1287/mnsc. 1080.0859

Leloup, B. and L. Deveaux, 2001. Dynamic pricing on the internet: Theory and simulations. J. Elec. Commerce Res., 1: 265-276. DOI: 10.1023/A:1011546021787

Leslie, P., 2004. Price discrimination in broadway theater. RAND J. Econ., 35: 520-541. 
Levin, Y., J. McGill and M. Nediak, 2009. Dynamic pricing in the presence of strategic consumers and oligopolistic competition. Manage. Sci., 55: 32-46. DOI: $10.1287 / \mathrm{mnsc} .1080 .0936$

Lieberman, W., 1992. Implementing yield management. ORSA/TIMS National Meeting, (San Francisco, California).

Littlewood, K., 1972. Forecasting and control of passenger bookings. Proceedings of the AGIFORS Symposium, (AGIFORS' 72), pp: 95-117.

Maglaras, C. and J. Meissner, 2006. Dynamic pricing strategies for multiproduct revenue management problems. Manufactur. Service Operat. Manage., 8: 136-148. DOI: $10.1287 / \mathrm{msom} .1060 .0105$

Plackett, R., 1983. Karl pearson and the chi-squared test. Int. Stat. Rev., 51: 59-72. DOI: 10.1007/978-14612-0103-8_1

PricewaterhouseCoopers, 2010. Official website of PricewaterhouseCoopers.
Rascher, D., 1999. A Test of the Optimal Positive Production Network Externality in Major League Baseball. In: Sports Economics: Current Research, Fizel, J., E. Gustafson and L. Hadley (Eds.), Westport, CT: Greenwood, ISBN-10: 0275963306, pp: 27-45.

Rosen, S. and A. Rosenfield, 1997. Ticket pricing. J. Law Econ., 40: 351-376.

Rothstein, M., 1971. An airline overbooking model. Trans. Sci., 5: 180-192.

Subrahmanyan, S. and R. Shoemaker. 1996. Developing optimal pricing and inventory policies for retailers who face uncertain demand. J. Retail., 72: 7-30. DOI: 10.1016/S0022-4359(96)90003-2

Zhao, W. and Y.S. Zheng, 2000. Optimal dynamic pricing for perishable assets with nonhomogeneous demand. Manage. Sci., 46: 375-388. DOI: 10.1287/mnsc.46.3.375.12063 